\title{
ENRICHING EMPLOYABILITY IN ENGINEERING EDUCATION BY THE DEVELOPMENT OF ENGLISH LANGUAGE THROUGH INTERNET
}

\author{
B. Sripala \\ M.A. \\ Research Scholar \\ KL University, Guntur
}

\begin{abstract}
English is considered to the Global language and is recognized by every country. English language has an ease to disseminate ideas, thoughts and feelings in an effective manner leading to economic, technological and cultural development. Especially, in the present day competitive world, in engineering education there is a growing need to mastery in English that would improve career prospects of students. Fresh engineering graduates need to develop the language based skills to be in the race in the present corporate world.

It is observed that, conventional class rooms are being replaced with language labs, class rooms with elearning aids. Internet is one of potentially powerful resources/tool for teaching English. Internet is useful to address some major concerns in the current teaching of English and also to investigate innovative ideas in current English Language Teaching (ELT) practices. Further, Internet is useful to create curriculum initiative through which students can be engaged in technologically based learniing of intercultural-cognitive nature. To accomplish this, the teacher can use technology i.e., computers, internet and other modern educational aids. The present paper discusses some of the strategies and practices to improve language skills of students using internet as a tool.
\end{abstract}

Key Words: English; Internet; Information and Communication Technology; Engineering Curriculum; Employability.

During 1960, Illinois University planned to teach students based on technology and it connected the computers so that students can gain information on a course when they are listening to lectures. Also, in 1960 professors from the University of Stanford decided to teach Mathematics while reading to young children by means of computers. Years passed and the use and the shape of using computers in educational technology changed. It was around 1990s that the World Wide Web entered into human beings' life. World Wide Web technology made teachers to rely on a method that has multi-object oriented sites and are either text-based or online virtual reality systems. Online education is vastly expanding and is trying to get the place of traditional methods of teaching and learning.

Today, millions of people worldwide are internet subscribers. A perusal of literature shows the use of internet in different educational and social settings including classrooms to aid teachinglearning methodology. It is observed that the use of internet in classrooms is still limited. Despite the fact that internet manifests itself as a good English language learning tool; they still need proof for educationalists, practitioners, teachers and decision makers. In this paper, an attempt is made to investigate the current usage and practices of internet 
ELK

Asia Pacific Journals

in the process of learning English language to enhance the skills of graduating engineers and make them industry ready.

\section{METHODOLOGY}

Students may need to acquire or have basic ICT skills in order to use an Internet lesson in the lab. In this context it implied incorporating elements of traditional non-ICT and ICT teaching i.e. using the Internet as a 'tool' for learning. The following recommendations can be made enhancing language skills of graduating students.

- Teachers should use sites and not rely on one lesson site just in case it does not work. Further, Teachers should not use too many sites, as this encourages students to rush through the sites working less conscientiously.

- Allocate time for engaging students for selecting sites.

- Teachers should be careful of choosing ELT-game sites; students were drawn to game sites when they should have been doing other tasks.

- Teachers ought to have a set of core Internet exercises for weaker students and additional exercises for students that finish earlier.

- Teachers need more time to prescreen and organize Internet materials so as to know which sites should be core for all students to cover.
ELK Asia Pacific Journals - Special Issue

ISBN: 978-81-930411-1-6

- Also, teachers should prepare which ones have to be additional for more able students.

- Teachers needed to make clear how Internet materials would relate to course exams.

Four broad Internet-using situations which are significantly distinctive that enhances the language skills are.

\section{Electronic Mail (E-mail)}

E-mail is the use of computer systems to transfer messages between users - now chiefly used to refer to messages sent between private mailboxes. Although it takes up only a relatively small domain of Internet 'space', by comparison with the billions of pages on the World Wide Web. Many of the messages that are incoming and outgoing, varied greatly in length and style. The diversity of e-mail contexts is more useful for language improvement.

\section{Chat groups}

Chat groups are continuous discussions on a particular topic, organized at particular Internet sites, in which computer users interested in the topic can participate. Sometimes, the interactions are stored in some format, and made available to users upon demand, so that they can catch up with the discussion, or add to it, at any time even after an appreciable period has passed. Thus enhancing the requisite cognitive and linguistic skills.

\section{Virtual worlds}

Virtual worlds are imaginary environments which people can enter to engage in text- based fantasy social interaction. The linguistic possibilities, 
ELK

Asia Pacific Journals

in such imagination-governed worlds, are plainly immense, but - as with all games - there need to be constraints guiding the play, without which the interactions would be chaotic.

\section{World Wide Web (WWW)}

The World Wide Web is the full collection of all the computers linked to the Internet which hold documents that are mutually accessible through the use of a standard protocol. The creator of the Web, computer scientist Tim BernersLee, has defined it as 'the universe of network-accessible information, an embodiment of human knowledge'.16 It was devised in 1990 as a means of enabling high-energy physicists in different institutions to share information within their field, but it rapidly spread to other fields, and is now all-inclusive in subject-matter, and designed for multimedia interaction between computer users anywhere in the world.

Based on these four situations, students acquire the rules to communicate via email, to talk in chat groups, to construct an effective Web page and to socialize in fantasy roles.

\section{CONCLUSION}

The internet is a good tool to learn English language vocabulary and grammar indirectly and this makes the learning task more engaging, enthusiastic, engaging and extended. The usage of internet lead to learn English, the internet is useful for language learning and internet-based materials could enhance language learning, the internet helped them acquire vocabulary, motivated them to learn English, and was an indispensable aid in the process
ELK Asia Pacific Journals - Special Issue

ISBN: 978-81-930411-1-6

of language acquisition. Using Information and Communication Technologies (ICT), particularly Internet, provides new opportunities for both students and teachers.

\section{REFERENCES}

[1] Biber, Douglas. 1988. Variation across speech and writing. Cambridge: Cambridge University Press.

[2] Borg, S. (2003) Teacher cognition in language teaching: A review of research on what language teachers think, know, believe and do. Language Teaching, 36: 81-109.

[3] Godwin-Jones, B. (1999) Emerging Technologies-Web Metadata. Language Learning and Technology, Vol 3 No1 July 1999: 12-16.

[4] Guskey, Thomas. (1989) Attitude and Perceptual Change in Teachers. International Journal of Education 13:7: 439-453.

[5] Kiely, R. (2001) Classroom evaluation - values, interests and teacher development. Language Teaching Research 5/3: 241-261.

[6] Li Lan. 2000. Email: a challenge to Standard English? English Today 64, 23-9, 55. National Association for the Teaching of English. 